\title{
CORRESPONDENCE
}

Correspondents are asked to be brief

Superannuation in an Integrated Health Service

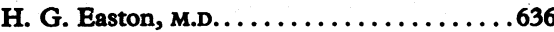

Malignant Hyperpyrexia

M. A. Denborough, F.R.A.C.P., and others. .636 Uterine Hypotonia

L. D. Courtney, M.R.C.o.G. . . . . . . . . . 637

Nitroprusside Revisited

M. Styles, F.F.A.R.C.S., and T. H. Taylor, F.P.A.R.C.S. ...................667

Ischaemic Colitis without Predisposing Cause

H. A. F. Dudley, F.R.C.S.ED., and I. Faris,

F.R.A.C.s. . . . . ...............6637

Rifampicin and Thrombocytopenia

G. C. Ferguson, M.R.C.P............638

Hospital Stafi Appointments

Paula J. H. Gosling, M.B.; A. J. Miller,

P.R.C.S.ED. $\quad \ldots \ldots \ldots \ldots \ldots \ldots \ldots \ldots \ldots \ldots 638$

Thromboplastin Reference Preparations

L. Poller, M.D., M.R.C.PATH............638
Spread of Cholera

H. G. Calwell, $M$

he New F.F.R.

C. G. Whiteside, B.M., F.F.R. . . . . . . .6639

Pupillary Paralysis after Tranquillizer

R. Pearson, M.SC., M.B..............6639

Circulatory Arrest and Bone Cement

E. Michelinakis, M.D., and others. .......6639

Blood Pressure, Anaesthesia, and Bone

Cement

P. Radford, M.B..

Diaznosis of Cystic Fibrosis

A. M. Deali, D.C.H. . . . . . . . .

Treatment of Opium Addiction

C. L. Anand, M.R.C.P.GLASG. . . . . . . . . .6640

Diazepam and Neuromuscular Blocking

Drugs

Sandra N. Webb, B.PHARM., and Elizabeth

G. Bradshaw, F.P.A.R.C.S............640

External Pressure and Venous Return

G. S. Makin, F.R.C.S. . . . . . . . . . . .6641
Scotland's Anaesthetists

G. D. Parbrook, F.F.A.R.C.S..........641

Neurofibromatosis with Leukaemia

M. W. McEvoy, M.B., and Jillian R. Mann,

M.R.C.P. ...................6641

Psychogeriatric Services

M. H. Davies, M.D., D.P.M. . . . . . . . . .641

Careers in Medicine

D. M. Bowers, L.R.C.P.ED... . . . . . . 641

IgE Levels in Asthmatics

D. Jacobs, F.I.M.L.T. . . . . . . . . . 642

Accident and Emergency Services

M. Ellis, F.R.C.s.; D. R. Richard, F.R.C.s.;

M. B. Heywood-Waddington, F.R.C.S. . . . . 642

Wegener's Granulomatosis

I. Friedmann, F.R.C.PATH... . . . . . . . . 643

Accidental Poisoning with Malathion

E. Sandi, PH.D................6643

Klackers' Wrists

J. Ashton, M.B.................6643
Superannuation in an Integrated Health Service

SIR,-A Scottish joint working party concluded ${ }^{1}$ that the case for integration of medical work is overwhelming and that a breaking down of artificial barriers between general practice, specialist practice, and community medicine is overdue. I suggest that, especially in times of inflation, differen superannuation regulations may hamper integration by complicating and, in some cases, penalizing, transfer from hospital or community medicine to general practice, or vice versa.

As the superannuation of hospital and community medicine staff depends on earnings during the last three years of service, it is protected from inflation until then. The value of this protection is shown by the calculation that if remuneration increased by $7 \cdot 2 \%$ annually, the benefit attributable to a given period of service (without change in incremental point or grading) would double every ten years. Because general-practitioner superannuation is based on career earnings the benefit derived from earlier years of service depreciates geometrically. To compensate (inadequately) for this earnings during later years, which will be greatest mainly because of inflation but partly because of the receipt of seniority allowances increasing each decade, are more heavily weighted in calculating benefit. Transfer to or from general practice entails loss of much of both forms of protection because benefit accrued by the time of transfer is frozen until retirement (except when a former hospital doctor obtains a post as a general-practitioner clinical assistant) and the period in general practice will not be long enough to attract full, if any, seniority allowances or increased weighting in calculating benefit.

Transfer might entail another penalty. If a former hospital doctor worked as a clinical assistant (or in a general-practitioner hospital), the whole of his hospital service would be assessed for superannuation at the rate for that grade even although this might be much less than that of his former post. On the other hand, this rule would be very advantageous if the rate of the former hospital post was less than that of the latter.

If work in any branch of the Health Service were taken into account in assessing general practitioner seniority payments and the weighting to be applied in calculating benefit (and if option were open to assess hospital work before transfer separately from that after), doctors who transferred to general practice would be near to parity with other general practitioners, but not with hospital or community medicine staff. Equity for general practitioners, including those who transfer to other work, would need some more radical change.

A fully integrated superannuation scheme, similar to the present hospital one, would simplify transfer to or from general practice and would give general practitioners much better protection against inflation than they now enjoy. In objection; it is said that a general practitioner's earnings may not be highest in his last years of service. With continuing inflation, this is unlikely to happen frequently, but the point could be met by basing superannuation calculations on the three best consecutive financial years, subsequent years (if any) being assessed separately. This provision could benefit hospital staff if they undertook fewer domiciliary consultations shortly before retiral, and it would benefit anyone who, for any reason, transferred to a less well remunerated post.

Himsworth ${ }^{2}$ considered that crystallization of career structures would endanger the healthy development of medical science. I suggest that it is important to modify the superannuation regulations, probably by introduction of a fully integrated scheme, so that interchange between hospital or community medicine and general practice is lets complicated and, sometimes, penalizing.-I am, etc.

Ruchill Hospital,

1 Doctors in an Integrated Health Service, p. 52, Scottish Home and Health Department, 2 Himsworth, H., Lancet, 1952, 2, 741.

\section{Malignant Hyperpyrexia}

SIR,-Your second leading article on malignant hyperpyrexia (21 August, p. 441) in just over three years ${ }^{1}$ emphasizes the clinical importance of this frequently fatal complication of anaesthesia.

However, we would like to stress that, in addition to suxamethonium and halothane, both ether and trichlorethylene can trigger off malignant hyperpyrexia, and that methoxyfluorane, cyclopropane, and chloroform are suspect. On the other hand, local, regional, or spinal anaesthesia is safe in individuals susceptible to malignant hyperpyrexia, and we have used this type of anaesthesia successfully many times over the past 11 years in susceptible individuals in a large family in which prior to 1960 there had been 10 deaths due to ether. If general anaesthesia is unavoidable, the best choice of anaesthetic at present would seem to be thiopentone, nitrous oxide, and D-tubocurarine.

Rather than assume that patients over 20 are likely to suffer from the non-rigid type of malignant hyperpyrexia and therefore not have an inherited anomaly, we would like to suggest that it would be safer to assume that all patients who develop malignant hyperpyrexia have an inherited disease of muscle, and that all their close relatives should be screened by serum creatine phosphokinase (CPK) estimations, so that other individuals at risk can be detected. By this means overt muscle disease in relatives may also be found. In fact, one of our patients with malignant 
hyperpyrexia associated with gross muscle rigidity was 54 .

Finally, we would like to suggest that all the clinical features of malignant hyperpyrexia might be explained in terms of single primary event. This primary event could be the continuous presence of excess calcium ions in the myoplasm. This would stimulate and sustain muscle contraction and also activate phosphorylase. ${ }^{2} 3$ The latter would keep up the supply of fructose 1, 6diphosphate for ATP production by glycolysis. Heat would be liberated during the continued synthesis and utilization of ATP and the lactic acid resulting from glycolysis would lead to the severe metabolic acidosis which occurs in malignant hyperpyrexia. The lactic acid would be transported to the blood stream, and in the liver part would be oxidized to provide the ATP necessary for converting the remainder to glucose. These transformations would lead to the liberation of much heat. Glucose synthesized in this way and from liver glycogen might then be transported to the muscle, where the processes activated by calcium ions would be permitted to continue. Liver and muscle mitochondria are both partly uncoupled by halothane and this would further increase heat production. Thus, muscle tissue aided by the liver would operate as a compound ATPase of great magnitude. The primary defect might well be located in that part of the sarcoplasmic reticulum associated with maintaining myoplasmic calcium ions at the level which does not stimulate contraction. -We are, etc.

M. A. Denborough F. J. R. HIRD J. O. KING

University Department of Medicine, Royal Melbourne Hospital,

Royal

Department of Biochemistry,

Victoria

1 British Medical Fournal, 1968, 3, 69.

Ozawa, E., Hosoi, K., and Ebashi, S., foumal of Biochemistry, 1967, 61, 531 .

3 Heilmeyer, L. M. G., jun., Meyer, F., Haschke, logical Chemistry, 1970, 245, 6649.

\section{Uterine Hypotonia}

SIR,-Further to Mr. H. K. Basu's letter (24 July, p. 251) the theory that uterine hypotonia results from a high level of fibrin degradation products (F.D.P.) leaves some questions unanswered.

Firstly, high levels of F.D.P. are also present in "the $70 \%$ " of cases of hypofibrinogenaemia in which postpartum haemorrhage does not occur. In $1969 \mathrm{Mr}$. Basu wrotel that "the occurrence of bleeding is not related to the degree of hypofibrinogenaemia," though it would seem that the level of F.D.P. must be so related.

Secondly, according to Bonnar et al. ${ }^{2}$ intravenous fibrinogen increases the level of F.D.P., yet to date this is the standard and most effective trearment of hypofibrinogenaemia, though heparin has also been used. In the National Maternity Hospital, Dublin, hypofibrinogenaemia with accidental haemorrhage is commonly encountered, and it has been found to be uniformly responsive to intravenous fibrinogen with adequate blood transfusion. ${ }^{3}$ Contrary to current theories no patient suffered ill effects from the treatment. If F.D.P. cause the hypotonia and if intravenous fibrinogen increases their level how does it control the bleeding? Thirdly, patients usually labour well after accidental haemorrhage whether coagulation failure occurs or not.

The suggestion that amniotic fluid causes hypotonia cannot yet be dismissed. Dr. D. F. Hawkins's criticisms (26 December 1970, p. 804) of my experiment (31 October 1970 p. 303) were taken into account. (The uterine muscle was a longitudinal midline fundal strip removed prior to elective caesarean section. Amniotic fluid was aspirated at the same time. The muscle was set up in a $40 \mathrm{ml}$ bath of oxygenated modified Krebs's solution at $37^{\circ} \mathrm{C}$ in which a control series had also been done. When the contractions had stabilized after three hours, $5 \mathrm{ml}$ of the amniotic fluid was introduced. Circumstances made it impossible to repeat the experiment.) The histological findings of amniotic fluid in the uterine blood vessels by different workers after hysterectomies fo persistent postpartum haemorrhage can hardly be regarded as coincidental. ${ }^{4-6}$ It seems clear that in some cases of coagulation failure postpartum hypotonia also occurs. The clinical evidence available is that both uterine hypotonia and coagulation failure are constant features of amniotic fluid infusion.

Last week I had another case of severe postpartum haemorrhage (5 pints; 2.7 1) following the expulsion of a dead fetus retained in utero for one month. The LeeWhite clotting time was 7 minutes, but the clot later partially dissolved, indicating the presence of fibrinogen with active fibrinolysis. The blood issuing per vaginam, however, did not clot, and bleeding continued despite fundal stimulation. The previously described measures (15 May, p. 403) were instituted and trickling continued through the pack. This time Trasylol was available and 200,000 units were given intravenously. The bleeding stopped immediately.-I am, etc.,

LOUIS COURTNEY

Department of Obstetrics and Gynaecology, General Hospital, 1 Basu, H. K., Foumal of Obstetrics and Gynae-
cology of the British Commonwealth, 1969, 76, 481.

Bonnar, J., McNicol, G. P., and Douglas, A. S. ournal of Obstetrics and Gynaecology of the British Commonwealth, 1969, 76, 799.
National Maternity Hospital, Dublin, Annual Reports, 1964-70.

ports, 1964-70. Medicine. 1950, 243, 590 .

$5 \mathrm{Josey,} W$ W. E., American fournal of Obstetrics and Josey, W. B., American foum

6 Attwood, H. D., personal communication, 1970.

\section{Nitroprusside Revisited}

SIR,-We were interested to read Dr. M. K. Mani's paper (14 August, p. 407) on the treatment of hypotensive crisis with the rarely used drug sodium nitropruscide. There is no mention, however, of the system of monitoring employed. In our experience with this drug in the production of hypotension during general anaesthesia its poten and evanescent nature makes continuous monitoring of both the infusion rate and the arterial blood pressure mandatory. We recommend the use of an automated drip rate recorder and direct arterial pressure monitoring for this purpose. ${ }^{1}$ We think it probable that these safeguards should be employed in the circumstances described in the paper.-We are, etc.,

M. StYLES

T. H. TAYLOR

London Hospital,

London E.1

1 Taylor, T. H., Styles, M., and Lamming, A. J.,

Ischaemic Colitis without

Predisposing Cause

SIR,-Drs. P. B. Cotton and M. Lea Thomas (3 July, p. 27) describe the association between the syndrome of ischaemic colitis and the taking of oral contraceptives. The following summary describes a patient with ischaemic colitis but without predisposing cause and without occlusion of vessels.

A 37-year-old woman was admitted with a 14-hour history of colicky lower abdominal pain, diarrhoea, and the passage of dark red blood per rectum. She had six to eight bowel actions and the pain was partly relieved by defaecation. She had vomited about six times. There was no significant past history. She had been taking six Veganin tablets (aspirin $250 \mathrm{mg}$, phenacetin $250 \mathrm{mg}$, codeine phosphate $10 \mathrm{mg}$ ) a day for the last week because of toothache. She was not taking oral contraceptives. On examination she was apprehensive; temperature $38^{\circ} \mathrm{C}$, pulse 88 , B.P. 130/75. There was tenderness in her lower abdomen and no masses were palpable. Sigmoidoscopy showed that there was blood coming from above the level reached but the mucosa was normal. Barium enema performed next day showed the features of ischaemic colitis between the hepatic flexure and the lower descending colon (Fig.). An abdominal aortogram performed several days later did not show any obstruction in the inferior mesenteric artery system.

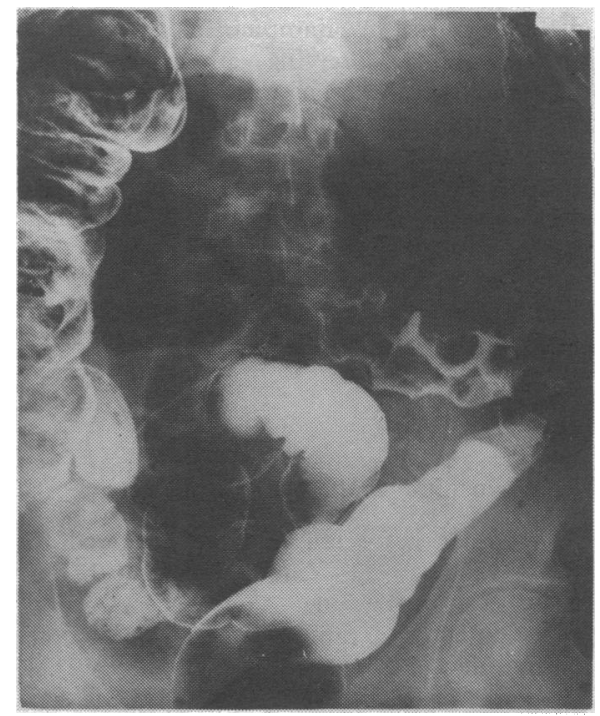

The acute episode settled, and she remained well for 12 months, when she began to complain of cramping left-sided abdominal pain associated with defaecation. This pain persisted over the next 12 months when barium enema showed narrowing of the upper part of the descending colon and what appeared to be a cluster of pseudodiverticula in this area.

Laparotomy was undertaken two and a half years after her initial admission. The 